DOI: $10.15679 /$ bjwr.v3i1.40

\title{
GENETIC DIVERSITY OF THE SIKA DEER CERVUS NIPPON IN LITHUANIA
}

\author{
Pūraitè I., Paulauskas A.. ${ }^{1}$
}

\begin{abstract}
Summary: The sika deer (Cervus nippon) are considered to be an invasive species in Europe. The main problem that the European free-living sika deer pose is damage they do to forests as well as hybridisation with the local red deer. The aim of this study was to analyse the genetic diversity of the sika deer and the red deer in Lithuania, and to determine the hybridization, which might be present in red deer population from the past release of sika deer into the nature.

Tissue samples were collected from 30 sika deer individuals from enclosures, and 33 wild-living red deer. Samples were genotyped using seven microsatellite (STR) loci; genetic diversity indices were calculated and individuals were classified using Principal Coordinate Analysis (PCoA); the genetic structure of sika deer and red deer was investigated according to Bayesian clustering method using STRUCTURE software.

The STR loci were highly polymorphic with up to 17 alleles per locus, and with an average heterozygosity $\mathrm{Ho}=0.695$ and $\mathrm{Ho}=0.626$ for sika deer and red deer respectively. Overall inbreeding coefficient $\left(\mathrm{F}_{\mathrm{IS}}\right)$ values are 0.004 and 0.127 in sika and red deer respectively. According to the PCoA sika deer samples differ from those of red deer; however, few red deer individuals mix with sika deer. These animals were attributed to red deer according to their phenotype; however according to their genotype they are closer to sika deer.

Thus, it can be concluded that wild red deer in Lithuania may hybridise with sika deer.
\end{abstract}

Key words: Cervus elaphus, Cervus nippon, genetic diversity, microsatellites

\section{Introduction}

The sika deer (Cervus nippon) is a ruminant originally comprising 13 subspecies (Whitehead, 1993) and distributed across Eastern Asia (Sheng, 1992; Shen-Jin et al., 2014). In Europe, sika deer are considered to be an invasive species. They were resettled to European zoos and enclosures from China, Japan, Korea, Taiwan, Russia and Vietnam (Mattioli, 2011). Sika deer were released or escaped from enclosures or other structures in the late 19th and early 20th centuries. For the first time the sika deer (Cervus nippon manthuricus) was introduced to Lithuania in 1954 from the Gorno-Altaysk area and released into the Dubrava forest near Kaunas (Central part of Lithuania). This sika deer herd consisted of 6 males and 18 females. Between 1954 and1992, the sika deer were found in Liepkalnis forest in Jonava region and Dubrava forest in Kaunas region, however since 1992 the sika deer had not been seen and recorded in the wild (Baleišis et al., 2003). Since 1988, the sika deer have been farmed in Kaunas region, Didžiosios Lapès. Ten years later, almost 750 sika deer were kept in enclosures in all Lithuania and the latest data from the Ministry of Environment indicate that currently there are approximately two thousand sika deer bred in enclosures.

Separate populations of sika deer established in other countries, such as the United Kingdom, Austria, the Czech Republic, Denmark, Finland, France, Germany, Poland, Western Russia and Ukraine (Bartoš, 2009, Perez-Espona et al., 2009). The main problem that the European free-living sika deer pose is damage they do to forests, as well as hybridisation with the local red deer, (Harrington, 1982; McDevitt et al., 2009; Lowe \& Gardiner, 1975; Goodman et al., 1999) in captivity (Harrington, 1973) and in the wild in the UK, the Czech Republic and New Zealand (Davidson, 1973; Lowe \& Gardiner, 1975; Harrington, 1979; Bartoš et al., 1981; Goodman et al., 1999).

\footnotetext{
${ }^{1}$ Pūraitė Irma., PhD; Paulauskas Algimantas., PhD, Faculty of Natural Sciences, Vytautas Magnus University, Vileikos 8, LT-44404 Kaunas distr., Lithuania.

Corresponding author: Paulauskas Algimantas e-mail: a.paulauskas@gmf.vdu.lt
} 
During the first year of the Lithuanian wildlife census in 1934, a total of 18 red deer were found in Žagare forest. It was believed that these animals came from Latvia. The other version is that the red deer dispersed into the forests of Žagare from the enclosure of Count Naryshkin. By the year 1982, the deer from Žagare forest had spread to other eight administrative regions. Small groups of deer have been observed in the other districts too. In order to facilitate the dispersal of the red deer, in 1969 attempts began to catch the deer and they were transferred to new locations. Most of the deer were released in Trakai (99), Vilnius (84) and Varena (82) regions. Currently, the red deer are widely spread throughout most parts of Lithuania.

Commonly used genetic markers in sika deer and red deer are bi-parental inheritated microsatellite (STR) markers (Nagata et al., 1998; Goodman et al., 1999; Okada \& Tamate 2000; Tamate et al. 2000; Goodman et al., 2001; Bonnet et al., 2002; Kuehn et al., 2003; Thevenon et al., 2003; Thevenon et al., 2004; McDevitt et al., 2009; Zachos et al., 2009; He et al., 2014; Radko et al., 2014; Shen-Jin et al., 2014; Szabolcsi et al., 2014; Ou et al., 2014) and maternally-inherited mitochondrial DNA markers (Tamate et al. 1998; Goodman et al., 1999; Wu et al. 2003; Nabata et al., 2004; Wu et al., 2005; Pitra \& Lutz, 2005; Pitra et al., 2005; Yuasa et al., 2005; Xiaoping et al., 2006; McDevitt et al., 2009; Ou et al., 2014) The aim of this study was to analyse the genetic diversity of the sika deer, to compare it with the diversity found in hunted red deer and to evaluate possible hybridization of the sika deer and the red deer in Lithuania.

\section{Material and Methods}

Tissue samples were collected from 30 sika deer in 2012 and 2013 from three enclosures in different localities in Lithuania and from 33 red deer in central and northern parts of Lithuania (Kèdainiai, Molètai, Panevėžys and Ukmerge districts), from legal hunted animals in the same period.

Total genomic DNA was extracted from muscle tissue using the Genomic DNA Purification Kit K\#0512 („Thermo Fisher Scientific Baltics“, Lithuania) according to the manufacturer's instructions. The microsatellite analysis was used to compare the genetic profiles of individual sika deer and wild red deer. Genotyping was based on seven microsatellites: RT1, RT23 (Wilson et al., 1997); NVHRT16, NVHRT21, NVHRT48, NVHRT73 (Roed \& Midthjell, 1998); BM888 (Bishop et al., 1994). The total reaction volume of $20 \mu \mathrm{l}$ contained $1 \mathrm{X}$ Taq buffer with $(50 \mathrm{mM} \mathrm{KCl}), 0.2 \mu \mathrm{M}$ of each primer, $0.2 \mathrm{mM}$ dNTPs, $2 \mathrm{mM} \mathrm{MgCl} 2$, 0.2 unit (U) Taq DNA polymerase, $50 \mathrm{ng}$ of the tested DNA and water. PCR mixture without DNA was used as a negative control for each reaction. The DNA amplification was performed in a MasterCycler gradient thermal cycler (Eppendorf AG, Germany), under the following conditions: an initial denaturation at $95{ }^{\circ} \mathrm{C}$ for 10 minutes, followed by 30 cycles of $95^{\circ} \mathrm{C}$ for 30 seconds, $54{ }^{\circ} \mathrm{C}$ or $52{ }^{\circ} \mathrm{C}$ (depending on the primer annealing temperature) for one minute and $72{ }^{\circ} \mathrm{C}$ for 90 seconds, the final extension at $72{ }^{\circ} \mathrm{C}$ for 10 minutes. PCR products were separated by capillary electrophoresis using the ABI3130 Genetic Analyser (Applied Biosystems Ltd., Germany). Prior to capillary electrophoresis, the PCR products were diluted 10 times with deionized formamide, and the DNA length standard GeneScan-500 LIZ was added to the solution.

Genotyping was based on electropherogramme peaks with the GeneMapper 4.0 programme (Applied Biosystems, Ltd., Germany). Evidence for null alleles, stutter-errors and large allele drop-out were checked using Micro-Checker version 2.2.3 software with 95\% confidence intervals (van Oosterhout et al. 2004). Identified allele size data was entered and processed with GenAlEx6.501 (Peakall \& Smouse, 2012), individuals were classified by Principal Coordinate Analysis (PCoA). Allelic richness values were calculated with FSTAT (Goudet, 1995). Coefficient FIS was calculated according to Weir and Cockerham and for the Hardy-Weinberg equilibrium estimation we followed the probability test approach using the program GENEPOP version 4.2 (Rousset, 2008).

Analysis of population and individual admixture was performed with a Bayesian clustering algorithm presented in STRUCTURE 2.3.4 (Falush et al., 2003; Hubisz et al., 2009). This model proposes that the K populations are each described by a set of allele frequencies at each locus. The two colours indicate the clusters of the different STRUCTURE. The model introduces a population structure by assigning the ancestry of individuals probabilistically to 1 or more populations. A Markov chain with 500000 iterations following a burn-in period of 500000 iterations was used. The probable number of clusters was determined 
by the delta K criterion with the STRUCTURE HARVESTER Web version 0.6.93 software (Earl \& von Holdt, 2012).

\section{Results}

Of the seven microsatellite markers tested, six could be amplified in sika deer and red deer. All amplified loci were polymorphic, null alleles were determined in three loci (NVHRT21 in the sika deer and NVHRT21, RT23, NVHRT16 in red deer). No evidence for stutter-errors and large allele drop-out were detected. Allelic richness data of the six microsatellites are given in Table 1. Pooling all the data, the mean number of alleles per locus was 9.17 in sika deer and 10.33 in red deer; the highest number of alleles (17) was detected at the NVHRT73 and NVHRT21 loci and the lowest (3) at the RT23 locus. Average allelic richness values were 5.004 and 5.659 for sika and red deer respectively. The observed heterozygosity (Ho) per locus was rather high, between 0.367 (RT23) and 0.967 (NVHRT48) with an average 0.695 heterozygosity in sika deer, and between 0.030 (RT23) and 1.000 (NVHRT48) with an average 0.626 in red deer. The overall inbreeding coefficient (FIS) values were 0.004 and 0.127 in sika and red deer respectively. Deviation from Hardy-Weinberg proportions was found in three and five out of six polymorphic loci in sika and red deer respectively.

Table 1: Diversity indices of Sika deer and Red deer populations in two alignments of our study

\begin{tabular}{|l|c|c|c|c|c|c|c|c|c|c|c|c|}
\hline & \multicolumn{9}{|c|}{ Sika deer } & \multicolumn{6}{c|}{ Red deer } \\
\hline \multicolumn{1}{|c|}{ Locus } & $\mathbf{N}$ & $\mathbf{N}_{\mathbf{A}}$ & $\mathbf{A}$ & $\mathbf{H}_{\mathbf{o}}$ & $\mathbf{H}_{\mathbf{e}}$ & $\mathbf{F}_{\text {IS }}$ & $\mathbf{N}$ & $\mathbf{N}_{\mathbf{A}}$ & $\mathbf{A}$ & $\mathbf{H}_{\mathbf{o}}$ & $\mathbf{H}_{\mathbf{e}}$ & $\mathbf{F}_{\text {IS }}$ \\
\hline NVHRT48 & 30 & 6 & 4.826 & 0.967 & 0.768 & -0.243 & 33 & 9 & 5.956 & 1.000 & 0.826 & -0.195 \\
\hline NVHRT73 & 30 & 17 & 7.995 & 0.933 & 0.897 & -0.024 & 33 & 13 & 7.558 & 0.879 & 0.798 & -0.085 \\
\hline NVHRT21 & 30 & 12 & 5.779 & 0.533 & 0.762 & 0.315 & 33 & 17 & 7.881 & 0.788 & 0.897 & 0.137 \\
\hline RT1 & 30 & 13 & 6.327 & 0.767 & 0.829 & 0.092 & 33 & 13 & 7.308 & 0.879 & 0.866 & 0.001 \\
\hline RT23 & 30 & 3 & 2.134 & 0.367 & 0.326 & -0.108 & 33 & 3 & 1.908 & 0.030 & 0.059 & 0.500 \\
\hline NVHRT16 & 30 & 4 & 2.963 & 0.600 & 0.584 & -0.010 & 33 & 7 & 3.345 & 0.182 & 0.299 & 0.406 \\
\hline Mean & $\mathbf{3 0}$ & $\mathbf{9 . 1 7}$ & $\mathbf{5 . 0 0 4}$ & $\mathbf{0 . 6 9 5}$ & $\mathbf{0 . 6 9 4}$ & $\mathbf{0 . 0 0 4}$ & $\mathbf{3 3}$ & $\mathbf{1 0 . 3 3}$ & $\mathbf{5 . 6 5 9}$ & $\mathbf{0 . 6 2 6}$ & $\mathbf{0 . 6 2 4}$ & $\mathbf{0 . 1 2 7}$ \\
\hline
\end{tabular}

$\mathrm{N}$ - sample size; NA - number of alleles; A - allelic richness; $\mathrm{H}_{0}$ - observed heterozygosity; He - expected heterozygosity; FIS - inbreeding coefficient.

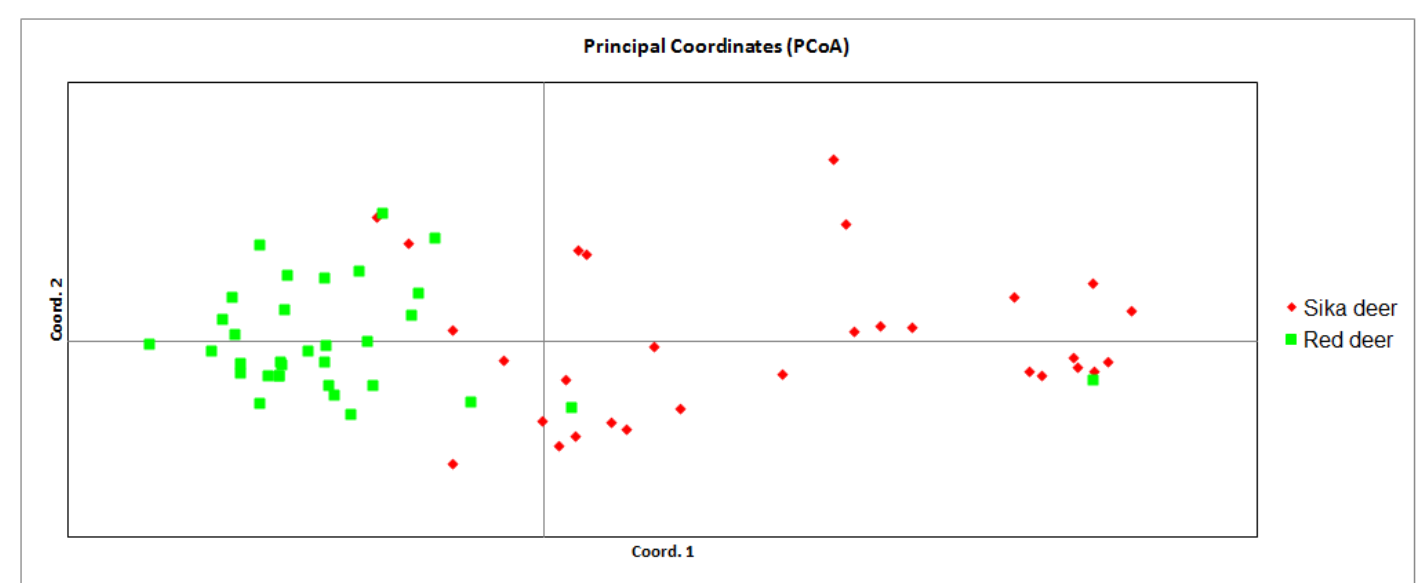

Figure 1. The principal coordinate analysis of sika deer and red deer populations in Lithuania. 


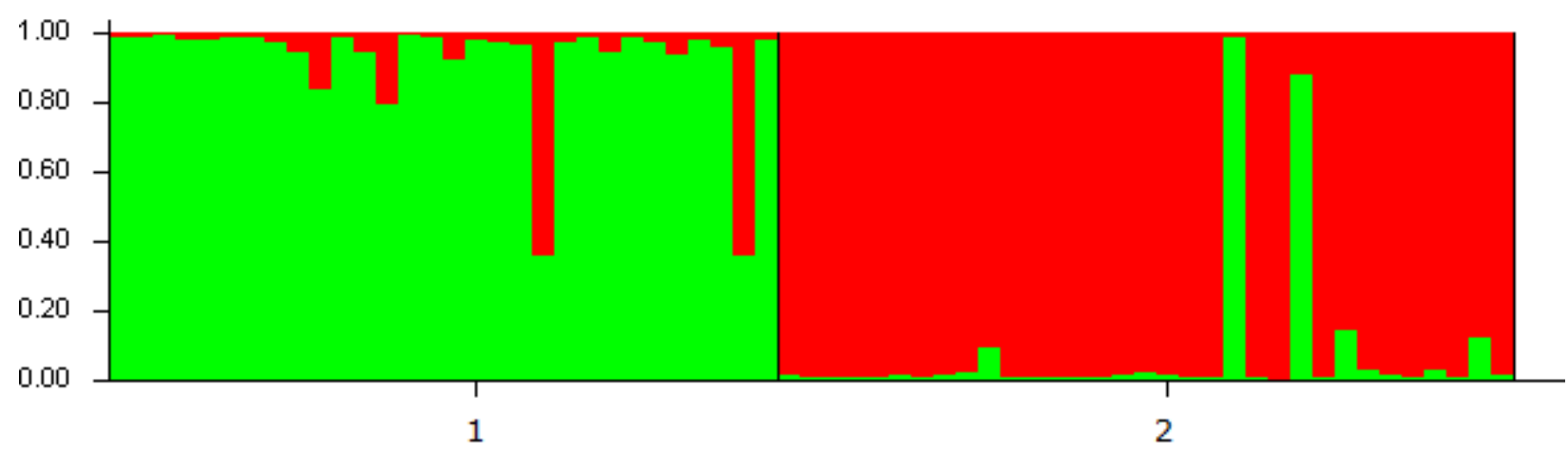

Figure 2. Individual-based clustering results: STRUCTURE results for $\mathrm{K}=2$. Sika deer - 1, red deer - 2.

According to the PCoA, samples of sika deer and red deer are slightly different, however, the two groups are not clearly separated. STRUCTURE analysis (Fig. 2) of both species microsatellite genotypes provided the strongest support for the grouping of the genetic variation into 2 clusters $(\mathrm{K}=2)$ based on $\Delta \mathrm{K}(451.799853)$. An important finding, as seen in Fig. 2, is the existence of individuals in sika deer population that were assigned to the red deer cluster and individuals of red deer population that were assigned to the sika deer cluster.

\section{Discussion}

Genetic analysis using microsatellite markers provides useful information in studying the population structure of animals. Loci used in this study have been used previously in the study of genetic diversity of red deer, roe deer (Capreolus capreolus), fallow deer (Dama dama) and reindeer (Rangifer tarandus) (Wilson et al.,1997; Roed \& Midthjell, 1998; Poetsch et al., 2001; Soriguer \& Rico, 2008; Haanes et al., 2011). So far, no data were published on genetic diversity of sika deer or red deer populations from Lithuania using microsatellites. Average number of alleles per locus in sika deer (9.17) and red deer (10.33) as well as the observed heterozygosity of the sika deer (0.695) and red deer (0.626) from Lithuania were within the range found previously in populations of these species. Higher diversity indices might be the result of a higher number of individuals analysed, larger sampling area or different set of microsatellite markers employed.

Our study showed that at some loci, observed and expected heterozygosity differed. The loci showing considerable differences in observed and expected heterozygosity levels were found to deviate from HardyWeinberg equilibrium. These deviations could be attributed to the presence of null alleles or to the limited sample size. Inbreeding coefficients for the sika deer and red deer were low, but similar to those found in previous studies (Nagata et al., 1998; Goodman et al., 1999; Okada \& Tamate, 2000; Tamate et al., 2000; Goodman et al., 2001; Kuehn et al., 2003; Thevenon et al. 2004; Frantz et al., 2008; McDevitt et al., 2009; He et al., 2014; Shen-Jin et al., 2014; Ou et al., 2014; Radko et al., 2014; Szabolcsi et al., 2014). This indicates free gene flow among animals, the absence of inbreeding.

Sika deer is assumed to be one of the most invasive introduced species in Europe (DAISIE, 2009). Therefore, it has been argued that immediate actions should be taken to impede quick expansion of this species (Nentwig et al., 2010). Originally from Japan, the sika deer are strongly genetically differentiated from the native red deer with which they hybridise (Goodman et al., 1999). Red deer are larger than sika, typically around $30 \mathrm{~cm}$ taller at the shoulders and whilst the red stags can grow antlers of 12 points or more, sika antlers rarely exceed eight points (Whitehead 1964, Harrington, 1973). Hybridisation is a problem in Europe in terms of the areas in which free-living red deer cross-breed with the sika deer (Goodman et al., 1999; Diaz et al., 2006; Bartoš, 2009; McDevitt et al., 2009; Senn \& Pemberton, 2009; Senn et al., 2010; Zachos \& Hartl, 2011). Our study also suggests the possibility of hybridization of the two species in the wild, as there were wild living specimens, which are attributed to red deer according to their phenotype, but are closer to sika deer according to their genotype. Until 1992, the sika deer were found in Kaunas and Jonava regions (central part of Lithuania), but since 1992 the sika deer have not been seen and recorded in the wild. The reasons of sika deer disappearing are not clear. Animals were not hunted and did not spread to 
other forests. It is considered that during this period in these areas the red deer spread and these two species began to intercross.

\section{References}

1. .Balčiauskas, L., Trakimas, G., Juškaitis, R., Ulevičius, A., Balčiauskienė, L. (1999). Atlas of Lithuanian mammals, amphibians and reptiles. Akstis (in Lithuanian).

2. .Baleišis, R., Bluzma, P., Balčiauskas, L. (2003). Hoofed animals of Lithuania. Akstis (in Lithuanian).

3. .Bartoš, L. (2009). Sika deer in Continental Europe. In: McCullough D.R., Takatsuki S. and Kaji K. (eds.). Sika Deer: Biology, Conservation and Management of Native and Introduced Populations, Tokyo: Springer, p. 573594.

4. Bartoš, L. Hyánek, J. Žirovnický, J. (1981). Hybridisation between red and sika deer 1. Craniological analysis. Zoologischer Anzeiger, 207: 260-270.

5. Bishop, M.D., Kappes, S.M., Keele, J.W., Stone, R.T., Sunden, S.L.F., Hawkins, G.A., Solonas-Toldo, S., Fries, R., Grosz, M.D., Yoo, J., Beattie, C.W. (1994). A genetic linkage map of cattle. Genetics 136: 619-639.

6. Bonnet A., Thevenon S., Maudet F., Maillard J.C. (2002). Efficiency of semi-automated fluorescent multiplex PCRs with 11 microsatellite markers for genetic studies of deer populations. Animal Genetics 33: 343-350.

7. DAISIE (2009). Handbook of Alien Species in Europe. Invading Nature: Springer Series in Invasion Ecology. Springer-Verlag. Dordrecht, Netherlands. Vol. 3.

8. Davidson, M. (1973). Characteristics, liberation and dispersal of sika deer (Cervus nippon) in New Zealand. New Zealand Journal of Forestry Science 3: 153-180.

9. Diaz, A., Hughes, S., Putman, R., Mogg, R., Bond, J.M. (2006). A genetic study of sika (Cervus nippon) in the New Forest and in the Purbeck region, southern England: is there evidence of recent or past hybridization with red deer (Cervus elaphus)? Journal of Zoology 270: 227-235.

10. Earl, D. A., von Holdt, B. M. (2012). Structure Harvester: a website and program for visualizing structure output and implementing the Evanno method. Conservation Genetics Resources vol. 4 (2): 359-361.

11. Falush, D., Stephens, M., Pritchard, J. K. (2003). Inference of population structure using multilocus genotipe data: linked loci and correlated allele frequencies. Genetics 164: 1567-1587.

12. Frantz, A.C., Hamann, J.L., Klein, F. (2008). Fine-scale genetic structure of red deer (Cervus elaphus) in a French temperate forest. European Journal of Wildlife Research 54(1): 44-52.

13. Goodman, S.J., Barton, N.H., Swanson, G., Abernethy, K., Pemberton, J.M (1999). Introgression through rare hybridization: A genetic study of a hybrid zone between red and sika deer (Genus Cervus) in Argyll, Scotland. Genetics 152: 355-371.

14. Goodman, S.J., Tamate, H.B., Wilson, R., Nagata, J., Tatsuzawa, S., Swanson, G.M., Pemberton, J.M., McCullough, D.R. (2001). Bottlenecks, drift and differentiation: the population structure and demographic history of sika deer (Cervus nippon) in the Japanese archipelago. Molecular Ecology 10: 1357-1370.

15. Goudet, J. (1995). FSTAT (Version 1.2): A computer program to calculate F-statistics. Journal of Heredity 86 (6): 485-486.

16. Haanes, H., Røed, K.H., Perez-Espona, S., Rosef, O. (2011). Low genetic variation support bottlenecks in Scandinavian red deer. European Journal of Wildlife Research 57: 1137-1150.

17. Harrington, R. (1973). Hybridization among deer and its implications for conservation. Irish Forestry Journal 30: 64-78.

18. Harrington, R. (1979). Some Aspects of the Biology and Taxonomy of the Deer of the County Wicklow Region, Ireland. National University of Ireland. PhD Thesis.

19. Harrington, R. (1982). The hybridization of red deer (Cervus elaphus L. 1758) and Japanese sika deer (C. nippon Temminck, 1838). In: International Congress of Game Biologists 14: 559-571.

20. He, Y., Wang, Z.-H., Wang, X.-M. (2014). Genetic diversity and population structure of a Sichuan sika deer (Cervus sichuanicus) population in Tiebu Nature Reserve based on microsatellite variation. Zoological Research 35(6): 528-536.

21. Hubisz, M. J., Falush, D., Stephens, M., Pritchard, J. (2009). Inferring weak population structure with the assistance of sample group informatikon. Molecular Ecology Resources 9: 1322-1332.

22. Kuehn, R., Schroeder, W., Pirchner, F., Rottmann, O. (2003). Genetic diversity, gene flow and drift in Bavarian red deer populations (Cervus elaphus). Conservation Genetics 4(2): 157-166.

23. Lowe, V.P.W., Gardiner, A.S., 1975. Hybridization between Red Deer and Sika Deer, with reference to stocks in north-west England. Journal of Zoology (London) 177: 553-566.

24. Mattioli, S. (Family Cervidae (Deer) chapter) (2011). In Wilson D.E. and Mittermeier R.A. ed., Handbook of the mammals of the world. Hoofed mammals. Lynx Edicions, Barcelona. Vol.2.

25. McDevitt, A.D., Edwards, C.J, O’Toole, P., O’Sullivan, P., O’Reilly, C., Carden, R.F. (2009). Genetic structure of, and hybridization between red (Cervus elaphus) and sika (Cervus nippon) deer in Ireland. Mammalian Biology 74: 263-273.

26. Nabata, D., Masuda, R., Takahashi, O. (2004). Bottleneck effects on the sika deer Cervus nippon population in Hokkaido, revealed by ancient DNA analysis. Zoological Science 21: 473-481.

27. Nagata, J., Masuda, R., Kaji, K., Ochiai, K., Asada, M., Yoshida, M.C. (1998). Microsatellite DNA variations of the sika deer, Cervus nippon, in Hokkaido and Chiba. Mammal Study 23: 95-101.

28. Nentwig, W., Kuhnel, E., Bacher, S. (2010). A generic impact scoring system applied to alien mammals in Europe. Conservation Biology 24: 302-311. 
29. Okada, A., Tamate, H.B. (2000). Pedigree analysis of the sika deer (Cervus nippon) using microsatellite markers. Zoological Science 17(3): 335-340.

30. Ou, W., Takekawa, S., Yamada, T., Terada, C., Uno, H., Nagata, J., Masuda, R., Kaji, K., Saitoh, T. (2014). Temporal change in the spatial genetic structure of a sika deer population with an expanding distribution range over a 15-year period. Population Ecology 56: 311-325.

31. Peakall, R., Smouse, P.E. (2012). GenAlEx 6.5: genetic analysis in Excel. Population genetic software for teaching and research-an update. Bioinformatics 28: 2537-2539.

32. Perez-Espona, S., Pemberton, J.M., Putman, R.J. (2009). Red and sika deer in the British Isles, current management issues and management policy. Mammalian Biology 74: 247-262.

33. Pitra, C., Lutz, W. (2005). Population genetic structure and the effect of founder events on the genetic variability of introduced sika deer, Cervus nippon, in Germany and Austria. European Journal of Wildlife Research 51: 95100.

34. Pitra, C., Rehbein, S., Lutz, W. (2005). Tracing the genetic roots of the sika deer Cervus nippon naturalized in Germany and Austria. European Journal of Wildlife Research 51: 237-241.

35. Poetsch, M., Seefeldt, S., Maschke, M., Lignitz, E. (2001). Analysis of microsatellite polymorphism in red deer, roe deer, and fallow deer - possible employment in forensic applications. Forensic Science International 116: $1-8$.

36. Radko, A., Zalewski, D., Rubiś, D., Szumiec, A. (2014). Genetic differentiation among 6 populations of red deer (Cervus elaphus L.) in Poland based on microsatellite DNA polymorphism. Acta Biologica Hungarica 65(4): 414-427.

37. Roed, K.H., Midthjell, L. (1998). Microsatellites in reindeer, Rangifer tarandus, and their use in other cervids. Molecular Ecology 7: 1771-1788.

38. Rousset, F. (2008). Genepop'007: a complete reimplementation of the Genepop software for Windows and Linux. Molecular Ecology Resources 8: 103-106.

39. Senn, H.V., Pemberton, J.M. (2009). Variable extent of hybridization between invasive sika (Cervus nippon) and native red deer (C. elaphus) in a small geographical area. Molecular Ecology 18: 862-876.

40. Senn, H.V., Swanson, G.M., Goodman, S.J., Bartons, N.H., Pemberton, J.M. (2010). Phenotypic correlates of hybridisation between red and sika deer (genus Cervus). Journal of Animal Ecology 79: 414-425.

41. Sheng, H.L. (1992). Cervus nippon. The Deer in China, East China Normal University Press, Shanghai (in Chinese)

42. Shen-Jin, L.V., Yan, Y., Xue-Bin, W. (2014). Genetic diversity analysis by microsatellite markers in four captive populations of the sika deer (Cervus nippon). Biochemical Systematics and Ecology 57: 95-101.

43. Soriguer, B.S.R., Rico, C. (2008). Cross-species tests of 45 microsatellite loci isolated from different species of ungulates in the Iberian red deer (Cervus elaphus hispanicus) to generate a multiplex panel. Molecular Ecology Resources 8: 1378-1381.

44. Szabolcsi, Z., Egyed, B., Zenke, P., Padar, Z., Borsy, A., Steger, V., Pasztor, E., Csanyi, S., Buzas, Z., Orosz, L. (2014). Constructing STR Multiplexes for individual identification of Hungarian red deer. Journal of Forensic Sciences 59(4): 1090-1099.

45. Tamate, H.B., Okada, A., Minami, M., Ohnishi, N., Higuchi, H., Takatsuki, S. (2000). Genetic variations revealed by microsatellite markers in a small population of the sika deer (Cervus nippon) on Kinkazan Island, Northern Japan. Zoological Science 17: 47-53.

46. Tamate, H.B., Tatsuzawa, S., Suda, K., Izawa, M., Doi, T., Sunagawa, K., Miyahira, F., Tado, H. (1998). Mitochondrial DNA variations in local populations of the Japanese sika deer, Cervus nippon. Journal of Mammalogy 79(4): 1396-1403.

47. Thevenon, S., Bonnet, A., Claro, F., Maillard, J.C. (2003). Genetic diversity analysis of captive populations: The Vietnamese sika deer (Cervus nippon pseudaxis) in zoological parks. Zoo Biology 22: 465-475.

48. Thevenon, S., Thuy, L.T., Ly, L.V., Maudet, F., Bonnet, A., Jarne, P., Maillard, J.C. (2004). Microsatellite analysis of genetic diversity of the Vietnamese sika deer (Cervus nippon pseudaxis). Journal of Heredity 95:1118.

49. van Oosterhout, C., Hutchinson, W.F., Wills, D.P.M., Shipley, P. (2004). MICROCHECKER: software for identifying and correcting genotyping errors in microsatellite data. Molecular Ecology Resources 4: 535-538.

50. Whitehead, G.K. (1964). The Deer of Great Britain on Ireland. Routledge and Kegan Paul, London.

51. Whitehead, G.K. (1993). The Whitehead Encyclopaedia of Deer. Swan Hill Press, Shrewsbury.

52. Wilson, G.A, Strobeck, C., Wu, L., Coffin, J.W. (1997). Characterization of microsatellite loci in caribou Rangifer tarandus, and their use in other artiodactyls. Molecular Ecology 6: 309-320.

53. Wu, H., Wan, Q.-H., Fang, S.-G. (2003). Two genetically distinct units of the Chinese sika deer (Cervus nippon): analyses of mitochondrial DNA variation. Biological Conservation 119: 183-190.

54. Wu, H., Wan, Q.-H., Fang, S.-G., Zhang, S.-Y. (2005). Application of mitochondrial DNA sequence analysis in the forensic identification of Chinese sika deer subspecies. Forensic Science International 148: 101-105.

55. Xiaoping, L., Fuwen, W., Ming, L., Guang, Y., Hai, L. (2006). Genetic diversity among Chinese sika deer (Cervus nippon) populations and relationships between Chinese and Japanese sika deer. Chinese Science Bulletin 51(4): 433-440.

56. Yuasa, T., Nagata, J., Hamasaki, S., Tsuruga, H., Furubayashi, K. (2005). The impact of habitat fragmentation on genetic structure of the Japanese sika deer (Cervus nippon) in southern Kantoh, revealed by mitochondrial Dloop sequences. Ecological Research 22: 97-106.

57. Zachos, F., Hajji, G.M., Hmwe, S.S., Hartl, G.B., Lorenzini, R., Mattioli, S. (2009) Population viability analysis and genetic diversity of the endangered red deer Cervus elaphus population from Mesola, Italy. Wildlife Biology 15(2): 175-186. 
58. Zachos, F.E., Hartl, G.B. (2011). Phylogeography, population genetics and conservation of the European red deer Cervus elaphus. Mammal Review 41(2): 138-150.

59. Weir, B. S., Cockerham, C. C. (1984). Estimating F-statistics for the analysis of population structure. Evolution 38: 1358-1370.

Received: 03.11.2015.

Accepted: 20.03.2016.

Pūraitè I., Paulauskas A..(2016) Genetic diversity of the sika deer cervus nippon in Lithuania. Balkan Journal of Wildlife Research, 3(1), pp. 19-25. 